\title{
Observed Variations in Turbulent Mixing Efficiency in the Deep Ocean
}

\author{
TAKASHI IJICHI ${ }^{\mathrm{a}}$ AND TOSHIYUKI HIBIYA \\ Department of Earth and Planetary Science, Graduate School of Science, The University of Tokyo, Tokyo, Japan
}

(Manuscript received 25 December 2017, in final form 10 May 2018)

\begin{abstract}
Recent progress in direct numerical simulations (DNSs) of stratified turbulent flows has led to increasing attention to the validity of the constancy of the dissipation flux coefficient $\Gamma$ in the Osborn's eddy diffusivity model. Motivated by lack of observational estimates of $\Gamma$, particularly under weakly stratified deep-ocean conditions, this study estimates $\Gamma$ using deep microstructure profiles collected in various regions of the North Pacific and Southern Oceans. It is shown that $\Gamma$ is not constant but varies significantly with the Ozmidov/ Thorpe scale ratio $R_{\mathrm{OT}}$ in a fashion similar to that obtained by previous DNS studies. Efficient mixing events with $\Gamma \sim O(1)$ and $R_{\mathrm{OT}} \sim O(0.1)$ tend to be frequently observed in the deep ocean (i.e., weak stratification), while moderate mixing events with $\Gamma \sim O(0.1)$ and $R_{\mathrm{OT}} \sim O(1)$ tend to be observed in the upper ocean (i.e., strong stratification). The observed negative relationship between $\Gamma$ and $R_{\mathrm{OT}}$ is consistent with a simple scaling $\Gamma \propto R_{\mathrm{OT}}^{-4 / 3}$ that can be derived from classical turbulence theories. In contrast, the observed results exhibit no definite relationships between $\Gamma$ and the buoyancy Reynolds number $\operatorname{Re}_{b}$, although $\operatorname{Re}_{b}$ has long been thought to be another key parameter that controls $\Gamma$.
\end{abstract}

\section{Introduction}

Turbulent mixing in the stratified ocean interior facilitates the conversion of available mechanical energy to background potential energy (Winters et al. 1995; Scotti and White 2014) and thus plays an important role in sustaining the density stratification and the associated global overturning circulation of the ocean (Munk and Wunsch 1998; Wunsch and Ferrari 2004). Actually, the pattern and magnitude of the global overturning circulation simulated by OGCMs are highly sensitive to how diapycnal eddy diffusivity $K_{\rho}$ is parameterized (e.g., Jayne 2009; Melet et al. 2013, 2014; de Lavergne et al. 2016; Mashayek et al. 2017). Most commonly used is the Osborn (1980) model that evaluates $K_{\rho}$ in terms of the TKE dissipation rate $\varepsilon$ and the background buoyancy frequency $N$ as

$$
K_{\rho}=\Gamma \frac{\varepsilon}{N^{2}}
$$

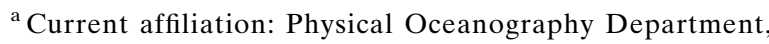
Woods Hole Oceanographic Institution, Woods Hole, Massachusetts.
}

Corresponding author: Takashi Ijichi, tijichi@whoi.edu where $\Gamma$ is conventionally treated as a global constant of 0.2 .

The dissipation flux coefficient $\Gamma$ is related to mixing efficiency (i.e., the ratio of the background potential energy gain to the available mechanical energy loss due to irreversible mixing) or the flux Richardson number $R_{f}$ as $\Gamma=R_{f} /\left(1-R_{f}\right)$. Conventionally, $R_{f}$ is defined as the ratio of the buoyancy flux term to the shear production term in the TKE equation. As noted by Venayagamoorthy and Koseff (2016), however, $R_{f}$ in this definition represents the mixing efficiency only for the case of stationary homogeneous shear-driven turbulence. Actually, for the case of convective-driven turbulence (Scotti 2015), the buoyancy flux represents not a sink of TKE to the background potential energy, but a source of TKE from the available potential energy, so that the conventional definition of $R_{f}$ is useless for a general representation of the mixing efficiency. To more rigorously account for irreversible energy conversions due to turbulent mixing, several authors (Peltier and Caulfield 2003; Venayagamoorthy and Koseff 2016) redefined $R_{f}$ as the ratio of the turbulent available potential energy (TAPE) dissipation (i.e., the background potential energy production) to the total turbulent energy dissipation. In this framework, $R_{f}$ directly represents the efficiency of irreversible mixing, and $\Gamma$ is given by the TAPE/TKE dissipation ratio. 
Vast observational efforts have been devoted to examining the validity of the constant $\Gamma$ in terms of the information such as $\varepsilon$ and the vertical heat flux (e.g., Yamazaki and Osborn 1993; Moum 1996; Davis and Monismith 2011; Walter et al. 2014), $\varepsilon$ and onedimensional heat budgets (Inall et al. 2000; Palmer et al. 2008; Simpson et al. 2015), $\varepsilon$ and the tracer dispersion (e.g., Ledwell et al. 2000, 2011), and $\varepsilon$ and the thermal variance dissipation rate $\chi_{T}$ (e.g., Oakey 1982; Peters and Gregg 1988; Ruddick et al. 1997; Oakey and Greenan 2004; Gregg and Horne 2009; Bluteau et al. 2013; Peterson and Fer 2014), although most of them are limited to a strongly stratified upper ocean and coastal regions. Of these, the method to estimate $\Gamma$ in terms of $\varepsilon$ and $\chi_{T}$ is most widely used and is based on the assumption that $K_{\rho}[(1)]$ is equivalent to diathermal diffusivity $K_{T}$ inferred from the Osborn and Cox (1972) model as

$$
K_{T}=\frac{\chi_{T}}{2 \Theta_{z}^{2}}
$$

where $\Theta_{z}$ is the background potential temperature gradient. This would be the most suitable observational method among others, because $\Gamma$ expressed in terms of the ratio of $\chi_{T}$ to $\varepsilon$ can be regarded as the approximate form of its recent definition in terms of the TAPE/TKE dissipation ratio. An accumulation of previous results thus obtained suggests $\Gamma \sim 0.2$, but with considerable scatter (Gregg et al. 2018). The scatter may simply result from the fact that stratification estimates are biased (Smyth et al. 2001; Arthur et al.2017), or the assumption of $K_{\rho} \sim K_{T}$ is violated under the presence of differential diffusion (Jackson and Rehmann 2014) or double diffusion (St. Laurent and Schmitt 1999). Otherwise, it may reflect physically meaningful variations of $\Gamma$ that should be explored further.

Direct numerical simulations (DNSs) of stratified turbulent flows have shown that values of $\Gamma$ are highly variable, depending on different triggering mechanisms and evolution stages of turbulent mixing. Smyth et al. (2001) showed that simulated $\Gamma$ varies by more than an order of magnitude over the time elapsed from the onset of Kelvin-Helmholtz (KH) instability: the shear-driven mixing is very efficient such that $\Gamma$ reaches $O(1)$ during the initial growth of $\mathrm{KH}$ billows, but $\Gamma$ decreases to $O(0.1)$ after the collapse of the billows into more complicated flows. They also showed that parameter $R_{\mathrm{OT}}$, defined as the ratio of the Ozmidov scale (Ozmidov 1965) to the Thorpe scale (Thorpe 1977), monotonically increases with time from $O(0.1)$ to $O(1)$, so that a negative relationship between $\Gamma$ and $R_{\mathrm{OT}}$ is obtained. Such time-dependent behavior, however, is not found for the case of convective-driven mixing. Scotti (2015) showed that efficient mixing with $\Gamma \sim O(1)$ and $R_{\mathrm{OT}} \sim O(0.1)$ found during the young stage of shear-driven mixing continues over the entire time from the onset of convective instability.

In addition to $R_{\mathrm{OT}}$, the buoyancy Reynolds number $\mathrm{Re}_{b}$, sometimes called the Gibson number, has been thought to be another key parameter that controls $\Gamma$. Shih et al. (2005) analyzed DNS data obtained during the mature stage of shear-driven mixing to show that $\Gamma$ decreases with $\operatorname{Re}_{b}$ as $\Gamma \propto \mathrm{Re}_{b}^{-1 / 2}$ for $\mathrm{Re}_{b}>100$, but keeps the conventional value of 0.2 for $7<\mathrm{Re}_{b}<100$. Although Bouffard and Boegman (2013) had confirmed this $\mathrm{Re}_{b}$ dependence of $\Gamma$ through a compilation of published laboratory and DNS data together with lake observations, several recent studies (Salehipour et al. 2016; Mashayek et al. 2017) noted that it is not valid for the young stage of shear-driven mixing.

The variability of $\Gamma$ thus demonstrated by a series of DNS studies has a significant impact on OGCM results (de Lavergne et al. 2016; Mashayek et al. 2017); its applicability to the real ocean, therefore, should be comprehensively assessed. However, there is little observational evidence supporting the variability of $\Gamma$ against $R_{\mathrm{OT}}$ and $\mathrm{Re}_{b}$. In particular, the previous estimates of $\Gamma$ were made mostly in the strongly stratified upper ocean, but rarely in the weakly stratified deep ocean where more obvious variations of $\Gamma$ might be observed.

This study therefore examines variations of $\Gamma$ using deep microstructure profiles collected in various regions of the North Pacific and Southern Oceans. Details of the data and methods are described in section 2. Observed spatial variations of $\Gamma$ and relationships of $\Gamma$ to $R_{\mathrm{OT}}$ and $\mathrm{Re}_{b}$ are presented in sections $3 \mathrm{a}$ and $3 \mathrm{~b}$, respectively. Furthermore, a theoretical scaling of $\Gamma$ consistent with the observed results is explored in section 3c. These results have important implications for underlying mechanisms of turbulent mixing, the applicability of the widely used Thorpe-scale-based parameterization of $\varepsilon$, and closure of the global overturning circulation, which are discussed in section 4. Finally, conclusions are presented in section 5 .

\section{Data and methods}

A total of 55 sets of hydrographic and microstructure profiles used in this study were collected in various regions of the western and central North Pacific Ocean and the Southern Ocean (Fig. 1; section 2a) with a free-falling vertical microstructure profiler VMP-5500 manufactured by Rockland Scientific International Inc. (http://www.rocklandscientific.com). The VMP-5500 recorded centimeter-scale fluctuations in velocity shear 

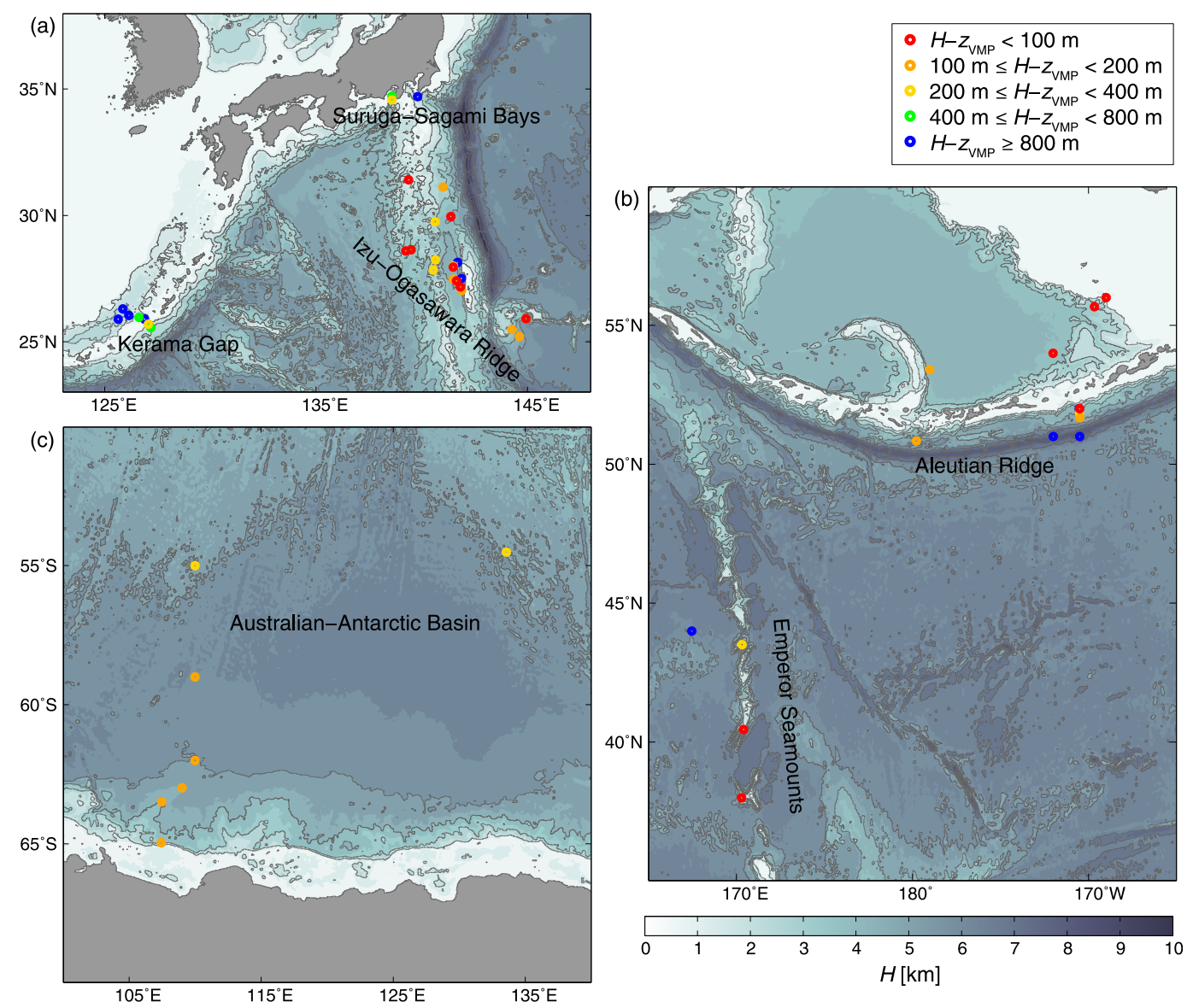

FIG. 1. Data collection sites in the (a) western and (b) central North Pacific Ocean and (c) Southern Ocean superposed on bathymetric contours with $1000-\mathrm{m}$ intervals. The color of each dot denotes the vertical distance of the maximum measurement depth from the bottom.

and temperature at a rate of $512 \mathrm{~Hz}$ while falling at a typical speed of $0.6 \mathrm{~m} \mathrm{~s}^{-1}$, from which $\varepsilon$ and $\chi_{T}$, respectively, were calculated (section $2 b$ ). Hydrographic parameters were measured with a SeaBird 3F/4C CTD mounted on the VMP-5500 (section 2c) so that spatial and temporal mismatches between the hydrographic and microstructure data could be avoided. Assuming that $K_{T}$ inferred from the Osborn and Cox (1972) model [(2)] is equivalent to $K_{\rho}$ inferred from the Osborn (1980) model [(1)], we estimated the dissipation flux coefficient $\Gamma$ as

$$
\Gamma=\frac{\left\langle\chi_{T}\right\rangle\left\langle N^{2}\right\rangle}{2\langle\varepsilon\rangle\left\langle\Theta_{z}\right\rangle^{2}},
$$

where the angle brackets denote an average over each turbulent patch identified from the Thorpe displacement profile $\delta_{T}$ (section 2d). For each turbulent patch, we also estimated the Thorpe scale $L_{T}=\left\langle\delta_{T}^{2}\right\rangle^{1 / 2}$, the Ozmidov scale $L_{O}=\left(\langle\varepsilon\rangle /\langle N\rangle^{3}\right)^{1 / 2}$, and the Kolmogorov scale $L_{K}=\left(\nu^{3} /\langle\varepsilon\rangle\right)^{1 / 4}$ with $\nu$ as the kinematic molecular viscosity and examined the relationship between $\Gamma$ and each of the Ozmidov/Thorpe scale ratio $R_{\mathrm{OT}}=L_{O} / L_{T}$ and the buoyancy Reynolds number $\operatorname{Re}_{b}=\langle\varepsilon\rangle /\left(\nu\left\langle N^{2}\right\rangle\right)=\left(L_{O} / L_{K}\right)^{4 / 3}$. Care must be taken in estimating the stratification for each turbulent patch (section 2e).

\section{a. Data collection sites}

Out of the total 55 VMP-5500 casts, 23 casts were made in the Izu-Ogasawara Ridge (Fig. 1a) during several cruises of the training vessel (T/V) OshoroMaru of Hokkaido University in November 2008 and December 2011 and the T/V Shinyo-Maru of Tokyo University of Marine Science and Technology in October 2012, October 2013, December 2014, and December 2016. Most of the casts reached down to within $200 \mathrm{~m}$ above the bottom. The Izu-Ogasawara Ridge is one of the prominent generation sites of semidiurnal internal tides (e.g., Niwa and Hibiya 2014) and crosses the critical latitude of $28.8^{\circ} \mathrm{N}$ for parametric subharmonic 
instability (PSI; McComas and Bretherton 1977) of the semidiurnal internal tides from north to south, so that PSI-induced strong turbulent mixing is expected (e.g., Hibiya et al. 2002). Actually, the microstructure data show higher dissipation rates in the Izu-Ogasawara Ridge (Fig. 2).

In the Aleutian Ridge (Fig. 1b), 11 casts were made during cruises of the T/V Oshoro-Maru in July 2007, June 2008, and June 2009. More than half of the casts reached down to within $200 \mathrm{~m}$ above the bottom. Although a significant amount of semidiurnal internal tidal energy is generated also in the Aleutian Ridge (e.g., Niwa and Hibiya 2014), most of it is thought to be unavailable for the local mixing because the Aleutian Ridge lies far north of the critical latitude for PSI of the semidiurnal internal tides (e.g., Hibiya et al. 2002). The microstructure data actually show lower dissipation rates in the Aleutian Ridge than in the Izu-Ogasawara Ridge (Fig. 2).

In the Australian-Antarctic Basin (Fig. 1c), seven casts were made during a cruise of the T/V UmitakaMaru of Tokyo University of Marine Science and Technology in January 2015. Most of the casts reached down to within $200 \mathrm{~m}$ above the bottom. There is growing evidence that turbulent mixing is greatly enhanced in strong frontal regions of the Antarctic Circumpolar Current (St. Laurent et al. 2012; Waterman et al. 2013; Sheen et al. 2013) and over the Antarctic continental slope (Mead Silvester et al. 2014; Fer et al. 2016), while being weak in most other regions of the Southern Ocean (Ledwell et al. 2011). Because the casts were made in non- or weak frontal regions of the Australian-Antarctic basin characterized by a smooth abyssal plain, much lower dissipation rates were observed (Fig. 2). Note that several density-compensated intrusions were observed, particularly in a transition zone between Lower Circumpolar Deep Water and Antarctic Bottom Water, where the method using (3) cannot be applied (section 2d).

In the Kerama Gap (Fig. 1a), seven casts were made during a cruise of the T/V Kagoshima-Maru of Kagoshima University in June 2013 (Nishina et al. 2016). The Kerama Gap is the deepest channel connecting the East China Sea to the northwestern North Pacific Ocean, where intermediate water is thought to be modified due to strong mixing over sills (Nakamura et al. 2013). Unfortunately, the VMP-5500 was tethered throughout the cruise because of trouble with a ballast release system, so the maximum depth of the casts was limited to $900 \mathrm{~m}$, leaving near-bottom mixing not fully observed.

In addition to the major datasets described above, we used small datasets collected over seamounts and in bays to include the most diverse oceanic environments

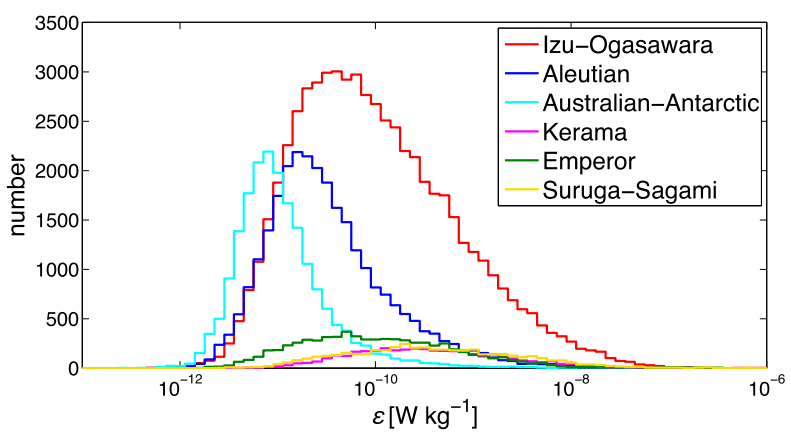

FIG. 2. Histogram of the TKE dissipation rate $\varepsilon$ in each observed region.

possible in the following analysis. During the cruises in July 2007 and June 2008, four casts were made over the Emperor Seamounts (Fig. 1b), where bottom-intensified mixing as observed over Fieberling Seamount (Kunze and Toole 1997; Toole et al. 1997) was expected. During the cruises in October 2012 and October 2013, three casts were made in the deep troughs of Suruga Bay and Sagami Bay (Fig. 1a), where large-amplitude internal tides had been observed (Ohwaki et al. 1991; Matsuyama et al. 1993; Kitade and Matsuyama 1997).

\section{b. Microstructure data processing}

Assuming isotropic turbulence, we calculated values of $\varepsilon$ every $2 \mathrm{~s}$ (approximately every $1 \mathrm{dbar}$ ) as

$$
\varepsilon=\frac{15}{2} \nu \int_{0}^{k_{\max }} \Psi_{\partial u / \partial z}(k) d k,
$$

where the vertical wavenumber shear spectrum $\Psi_{\partial u / \partial z}(k)$ was smoothed over a bin width of $6 \mathrm{~s}$ with halfoverlapping 2-s Hanning windows and was corrected for the shear probe response (Macoun and Lueck 2004) and vehicular vibrations (Goodman et al. 2006). The upper integration limit $k_{\max }$ was set to the corresponding Kolmogorov wavenumber $k_{K}=(2 \pi)^{-1}\left(\varepsilon / \nu^{3}\right)^{1 / 4}$ if $k_{K}$ was less than $50 \mathrm{cpm}$, but was otherwise set to $50 \mathrm{cpm}$, beyond which $\Psi_{\partial u / \partial z}(k)$ appeared to be dominated by electronic noise (Fig. 3). If $k_{\max }=50 \mathrm{cpm}<k_{K}$, the variance contained in the corresponding Nasmyth spectrum (Wolk et al. 2002) between $k_{\max }$ and $k_{K}$ was added to that in (4).

The calculation of $\chi_{T}$ was performed in a manner similar to that for the calculation of $\varepsilon$, but in a more careful fashion due to the required resolution. Prior to this, each fast-response FP07 thermistor profile was calibrated against the concurrent SeaBird temperature profile with polynomial regression and first-differenced to yield a high-resolution temperature gradient profile. Values of $\chi_{T}$ were then calculated from the temperature 
(a)

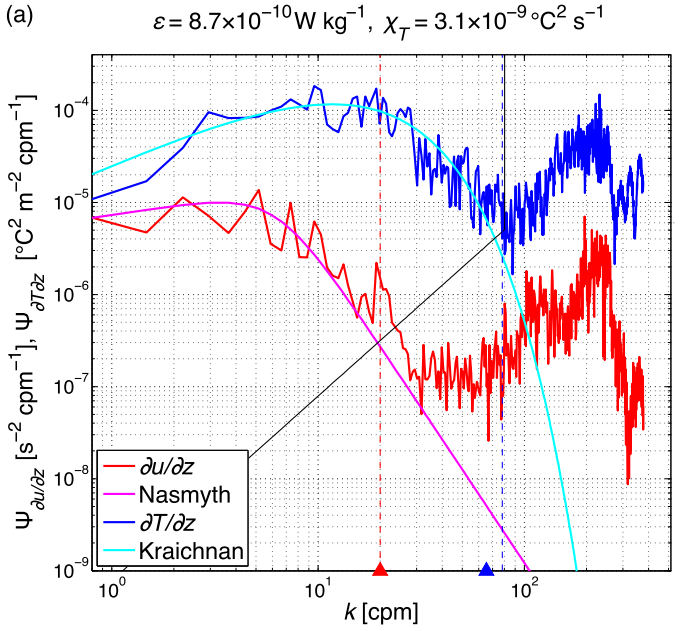

(b)

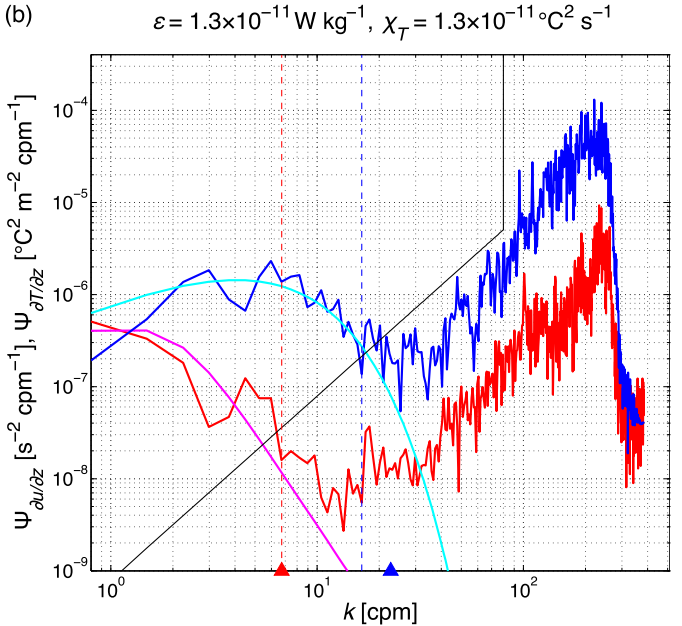

FIG. 3. Samples of the vertical wavenumber shear spectrum $\Psi_{\partial u / \partial z}(k)$ and the temperature gradient spectrum $\Psi_{\partial T / \partial z}(k)$, together with the corresponding theoretical spectra for the case of (a) stronger or (b) weaker dissipation. The Kolmogorov wavenumber $k_{K}$ and the Batchelor wavenumber $k_{B}$ are denoted by the red and blue triangles, respectively. The upper integration limits in (4) and (5) are denoted by the red and blue dashed lines, respectively. The threshold noise level for $\Psi_{\partial T / \partial z}(k)$ is denoted by the black line.

gradient spectrum $\Psi_{\partial T / \partial z}(k)$ under the assumption of isotropic turbulence as

$$
\chi_{T}=6 \kappa \int_{0}^{k_{\max }^{\prime}} \Psi_{\partial T / \partial z}(k) d k,
$$

where $\kappa$ is the thermal molecular diffusivity, and $\Psi_{\partial T / \partial z}(k)$ was smoothed over the same bin width as $\Psi_{\partial u / \partial z}(k)$ and corrected for first differencing and the thermistor response (Goto et al. 2016). The upper integration limit $k_{\max }^{\prime}$ was set to the highest vertical wavenumber for which $\Psi_{\partial T / \partial z}(k)$ exceeded a threshold noise level [slightly modified from Rainville and Winsor (2008) and denoted by the black line in Fig. 3]. If $k_{\max }^{\prime}$ was less than the corresponding Batchelor wavenumber $k_{B}=(2 \pi)^{-1}\left[\varepsilon /\left(\nu \kappa^{2}\right)\right]^{1 / 4}$, the variance contained in the corresponding Kraichnan spectrum (Bogucki et al. 2012) between $k_{\max }^{\prime}$ and $k_{B}$ was added to that in (5). This compensation, however, was not sufficient if the integration range was too narrow to resolve the broad spectral peak of $\Psi_{\partial T / \partial z}(k)$ at $k \sim k_{B} / 5$. Following Bluteau et al. (2017), we calculated $\chi_{T}$ only when $k_{\max }^{\prime}>k_{B} / 3$, discarding more than $20 \%$ of the data in extremely weak stratification below $4000 \mathrm{~m}$ in contrast to no more than $10 \%$ of the data in the uppermost $3000 \mathrm{~m}$.

\section{c. Hydrographic data processing}

Spurious salinity spikes arising from dissimilar response characteristics of the SeaBird conductivitytemperature (CT) sensors (Horne and Toole 1980) and thermal inertia of the conductivity cell (Lueck and Picklo 1990) were substantially reduced by applying several filters to CT signals. These included a response-matching filter estimated from the crossspectrum of CT (Anderson 1993) and a thermal-lag correction filter (Morison et al. 1994). A median filter was also applied to CT with bin widths ranging from 2 to 20 dbar that were determined by the amount and size of residual salinity spikes. In return, however, genuine overturns would also be smoothed out by this SeaBird data processing. To overcome this problem, we combined the high-resolution FP07 data with the smoothed SeaBird data to estimate $\left\langle\Theta_{z}\right\rangle$ and $\left\langle N^{2}\right\rangle=g \alpha\left\langle\Theta_{z}\right\rangle\left(1-1 / R_{\rho}\right)$ in (3), where $g$ is the gravitational acceleration, $\alpha$ is the thermal expansion coefficient, and $R_{\rho}$ is the density stability ratio defined as $\left(\alpha\left\langle\Theta_{z}\right\rangle\right) /\left(\beta\left\langle S_{z}\right\rangle\right)$ with the saline contraction coefficient $\beta$ and the vertical salinity gradient $S_{z}$. The SeaBird temperature data were used only for the estimate of $R_{\rho}$, whereas the FP07 temperature data were used for the estimate of $\left\langle\Theta_{z}\right\rangle$ independent of $R_{\rho}$. In addition, the Thorpe displacement $\delta_{T}$ was calculated from FP07derived potential temperature $\Theta$ (see section $2 \mathrm{~d}$ for more details). Here, we used the FP07 temperature data decimated to $32 \mathrm{~Hz}$ (approximately $50 \mathrm{cpm}$ ) with a boxcar window to avoid possible contamination by the sensor electronic noise (Fig. 3).

\section{d. Turbulent patch identification}

Following Mater et al. (2015), we identified each turbulent patch using the cumulative Thorpe displacements $\Sigma \delta_{T}: \Sigma \delta_{T}$ remains nonzero within a patch but becomes zero at its boundaries (Fig. 4c). If the width of a turbulent patch thus identified was less than 5 dbar, several adjacent patches were merged into one composite patch whose width became larger than 5 dbar (Fig. 4f), so as to 

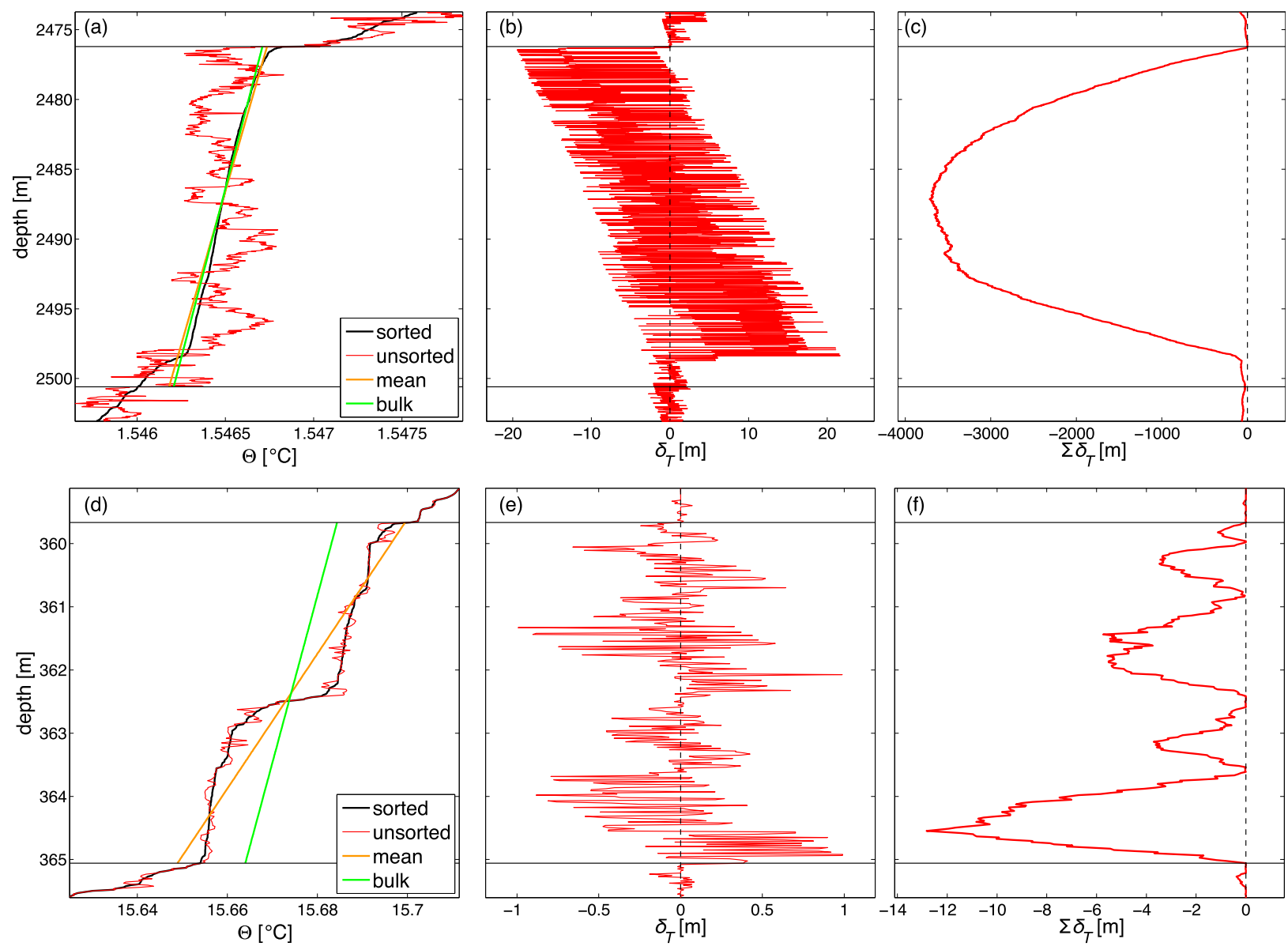

FIG. 4. Samples of the (left) potential temperature $\Theta$, (center) Thorpe displacement $\delta_{T}$, and (right) cumulative Thorpe displacements $\Sigma \delta_{T}$ for the case that the turbulent patch enclosed by the horizontal lines is identified (top) without or (bottom) with the merging process.

inevitably include bins for the calculations of $\varepsilon$ and $\chi_{T}$ (section $2 \mathrm{~b}$ ). Here, $\delta_{T}$ was calculated as the difference in depth of each fluid parcel between the unsorted and sorted profiles of $\Theta$ (Figs. 4b,e). Since $\Theta$ was used as a surrogate for potential density, a near-surface temperature minimum layer at high latitudes must be excluded from this reordering process. We therefore excluded the uppermost 500-m layer in the Aleutian Ridge and the uppermost 800-m layer in the Australian-Antarctic basin, but the uppermost 50-m layer otherwise. We also excluded turbulent patches with $-1 / 2 \leq R_{\rho} \leq 2$ from the estimate of $\Gamma[(3)]$ to avoid possible contamination by strongly salinity-stratified layers and densitycompensated intrusions (St. Laurent and Schmitt 1999). No minimum criteria were set here for the estimate of the Thorpe scale $L_{T}=\left\langle\delta_{T}^{2}\right\rangle^{1 / 2}$ since $\delta_{T}$ was calculated with high-resolution FP07 temperature.

\section{e. Patch-averaged stratification}

There are two types of $\left\langle\Theta_{z}\right\rangle$ that should be carefully selected (Smyth et al. 2001): a mean gradient $\left\langle\Theta_{z}\right\rangle_{\text {mean }}$ calculated through linear fitting of the sorted $\Theta$ profile and a bulk gradient $\left\langle\Theta_{z}\right\rangle_{\text {bulk }}$ calculated as $\left\langle\Theta_{z}\right\rangle_{\text {bulk }}=$ $\left\langle\Theta^{\prime 2}\right\rangle^{1 / 2} / L_{T}$, where $\Theta^{\prime}$ is the difference between the unsorted and sorted $\Theta$ values at each depth. Both gradients are nearly equal if a single overturn dominates over a patch (Fig. 4a), whereas $\left\langle\Theta_{z}\right\rangle_{\text {mean }}$ tends to be larger than $\left\langle\Theta_{z}\right\rangle_{\text {bulk }}$ if a patch consists of multiple overturns separated by nonoverturning thin stable layers (Fig. 4d). On the basis of DNS results, Smyth et al. (2001) suggested that $\left\langle\Theta_{z}\right\rangle_{\text {bulk }}$ and $\left\langle\Theta_{z}\right\rangle_{\text {mean }}$ should be used for the estimates of the Ozmidov scale $L_{O}$ and $\Gamma$ [(3)], respectively, which is actually adopted hereinafter. The validity of this method is confirmed in the appendix.

\section{Results}

\section{a. Observed spatial variations of $\Gamma$}

We first examine the validity of the constant $\Gamma$ in the stratified ocean interior that has been widely assumed. Figure 5 shows histograms of $\Gamma$ classified in terms of 

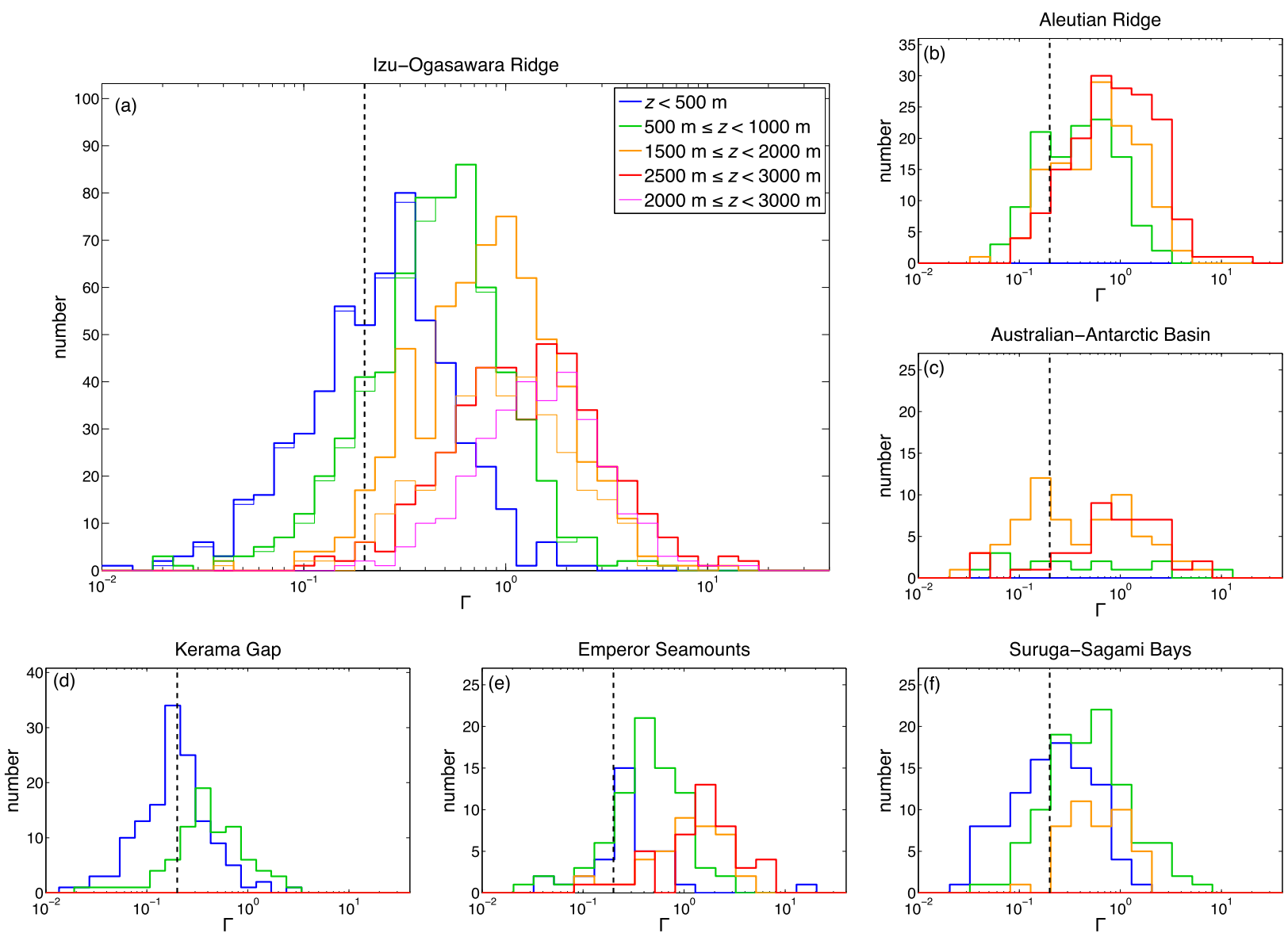

FIG. 5. Histograms of $\Gamma$ classified in terms of regions and depth ranges. Turbulent patches with $\operatorname{Re}_{b} \leq 40$ are not counted in these histograms. Note that thin lines in (a) show additional histograms of $\Gamma$ in the Izu-Ogasawara Ridge using only turbulent patches with $\left\langle\chi_{T}\right\rangle$ larger than $5.8 \times 10^{-11}{ }^{\circ} \mathrm{C}^{2} \mathrm{~s}^{-1}$, the median of the $\chi_{T}$ distribution in this region.

regions and depth ranges. Note that turbulent patches with $\mathrm{Re}_{b} \leq 40$ were not counted in these histograms, which might be affected by differential diffusion (Jackson and Rehmann 2014) and anisotropic turbulence (Yamazaki and Osborn 1990). This exclusion caused the decrease of available patches, particularly in the Australian-Antarctic basin where extremely low dissipation rates were observed (Fig. 2), resulting in the distribution of $\Gamma$ far from reliable (Fig. 5c). We therefore begin with the histograms of $\Gamma$ in the Izu-Ogasawara Ridge (thick lines in Fig. 5a), the most reliable ones because of their larger number of patch elements with higher dissipation rates (Fig. 2). It is apparent that observed $\Gamma$ varies widely in a lognormal fashion as observed by the previous studies (Moum 1996; Ruddick et al. 1997). Of special notice is that the peak of the histogram significantly shifts to a larger value as the depth deepens: the peak is found near the conventional value of 0.2 in the uppermost $500 \mathrm{~m}$, largely consistent with the previous observations as reviewed by
Gregg et al. (2018), but beyond 1 in a depth range of 2500-3000 m. Such a tendency can be found also in the other regions (Figs. 5b-f), although the number of elements in each histogram may not be sufficient.

However, there is a concern that the observed larger values of $\Gamma$ in the deeper ocean might be contaminated by noise: $\Gamma[(3)]$ might be overestimated if low values of $\chi_{T}$ were not fully resolved. To address this concern, we show additional histograms of $\Gamma$ in the Izu-Ogasawara Ridge (thin lines in Fig. 5a) using only turbulent patches with $\left\langle\chi_{T}\right\rangle$ larger than the median of the $\chi_{T}$ distribution in this region (specifically, $5.8 \times 10^{-11}{ }^{\circ} \mathrm{C}^{2} \mathrm{~s}^{-1}$ ). A similar peak shift with depth can also be found from these histograms. On this basis, we believe that the observed spatial variations of $\Gamma$ are actually reflecting the nature of oceanic turbulence. This result suggests the highly variable nature of $\Gamma$ and, more importantly, larger values of $K_{\rho}$ as well as $\Gamma$ than previously thought, particularly in the deep ocean, whose possible impacts on closure of the global overturning circulation are discussed in section $4 \mathrm{c}$. 
(a)

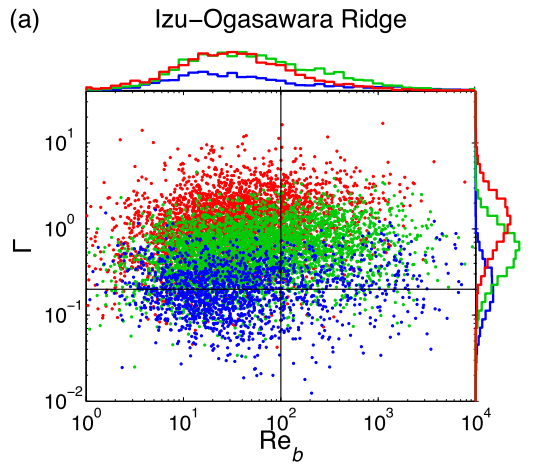

(d)

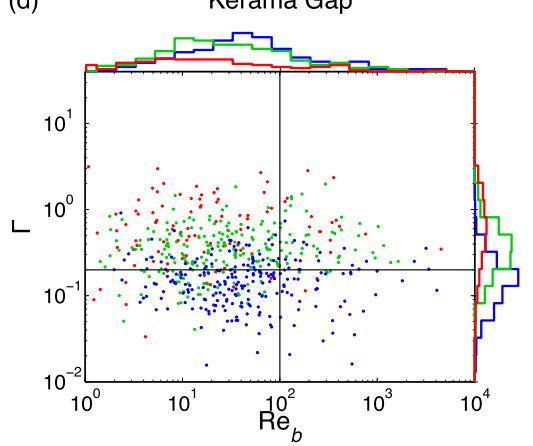

(b)

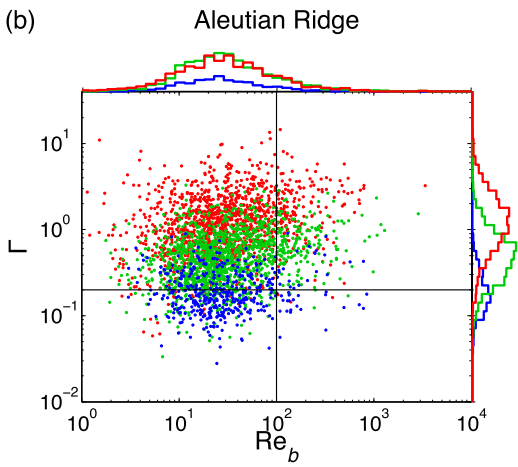

(e)

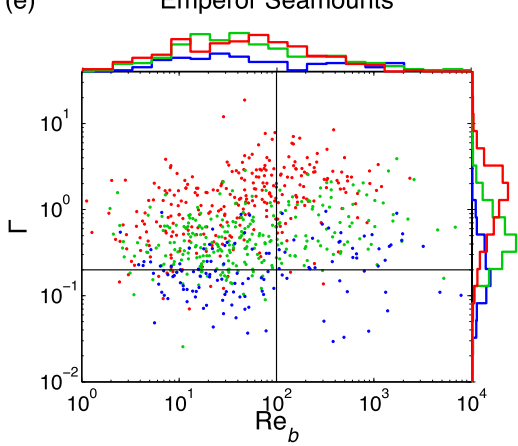

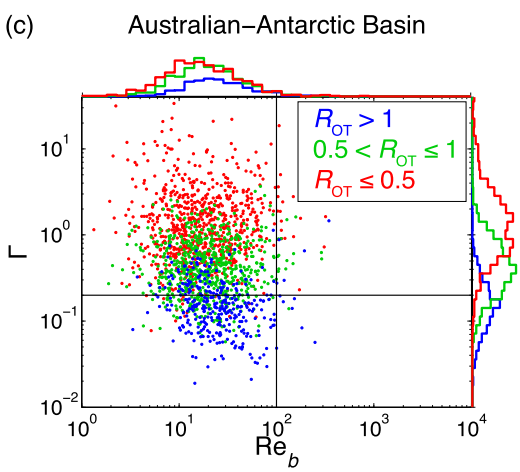

(f)

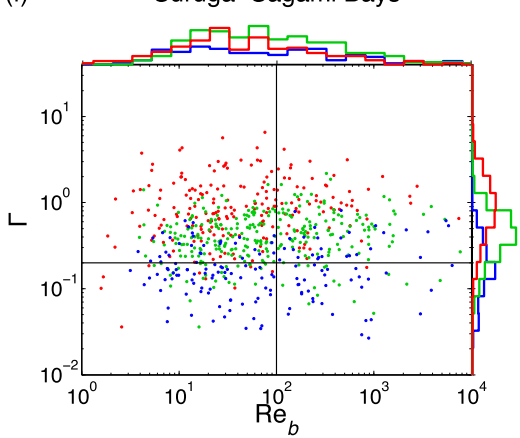

FIG. 6. Observed variations of $\Gamma$ against $\mathrm{Re}_{b}$ classified in terms of regions and $R_{\mathrm{OT}}$ ranges.

\section{b. Observed relationships of $\Gamma$ to $R_{\mathrm{OT}}$ and $\mathrm{Re}_{b}$}

We next address which parameter controls the variations of $\Gamma$ thus observed (section 3a). Here, we focus on two observed parameters, $\operatorname{Re}_{b}$ and $R_{\mathrm{OT}}$, although there might be some other parameters controlling $\Gamma$, such as the Richardson number (Mashayek et al. 2013) and the Reynolds number (Mashayek and Peltier 2013). Figures 6 and 7 show observed variations of $\Gamma$ against $\operatorname{Re}_{b}$ and $R_{\mathrm{OT}}$. It appears that there are no definite relationships between $\Gamma$ and $\operatorname{Re}_{b}$ regardless of the observed regions (see scatterplots in Fig. 6 and histograms of $\Gamma$ in Fig. 7). In particular, the scatterplots for $R_{\mathrm{OT}}>1$ (blue dots in Fig. 6) do not support the negative relationship $\Gamma \propto \mathrm{Re}_{b}^{-1 / 2}$ for $\mathrm{Re}_{b}>100$ suggested from the previous DNS studies on the mature stage of shear-driven mixing (Shih et al. 2005; Bouffard and Boegman 2013). ${ }^{1}$ Nor from several previous observations (Peters and Gregg 1988; Ruddick et al. 1997) can this negative relationship be found, suggesting that $\mathrm{Re}_{b}$ is not a major parameter controlling $\Gamma$ in the ocean interior, whose theoretical arguments are explored at the end of section $3 \mathrm{c}$.

\footnotetext{
${ }^{1}$ Remember that $R_{\mathrm{OT}}>1$ corresponds to the mature stage of shear-driven mixing according to Smyth et al. (2001), as introduced in section 1.
}

In contrast, significant variations of $\Gamma$ against $R_{\mathrm{OT}}$ can be confirmed regardless of the $\mathrm{Re}_{b}$ ranges and the observed regions (see scatterplots in Fig. 7 and histograms of $\Gamma$ in Fig. 6): $\Gamma \sim O(1)$ for $R_{\mathrm{OT}} \sim O(0.1)$, whereas $\Gamma \sim$ $O(0.1)$ for $R_{\mathrm{OT}} \sim O(1)$. Such negative relationship was also obtained by Smyth et al. (2001) through the analysis of upper-ocean datasets as well as DNS results. Note that we used the deep-ocean datasets to confirm the negative relationship between $\Gamma$ and $R_{\mathrm{OT}}$ for the range of $R_{\mathrm{OT}}$ lower than that covered by Smyth et al. (2001). Combining this observed result and the previous DNS results gives an insight into underlying mechanisms of deep-ocean mixing, which is discussed in section $4 \mathrm{a}$. In addition, the observed significant variations of $R_{\mathrm{OT}}$ (Fig. 7) suggest the limitation of the validity of the Thorpe-scale-based parameterization of $\varepsilon$ that has been widely applied to hydrographic datasets, which is discussed in section $4 \mathrm{~b}$.

\section{c. Theoretical scaling of $\Gamma$ in terms of $R_{\mathrm{OT}}$}

In the high Reynolds number limit, turbulent dissipation is assumed to be controlled by energy supply from large-scale eddies rather than by viscosity. According to Taylor (1935), the size of the largest eddies $L$ responsible for most of the turbulence production is expressed in terms of the TKE density $k_{\mathrm{TKE}}$ and $\varepsilon$ as 
(a)

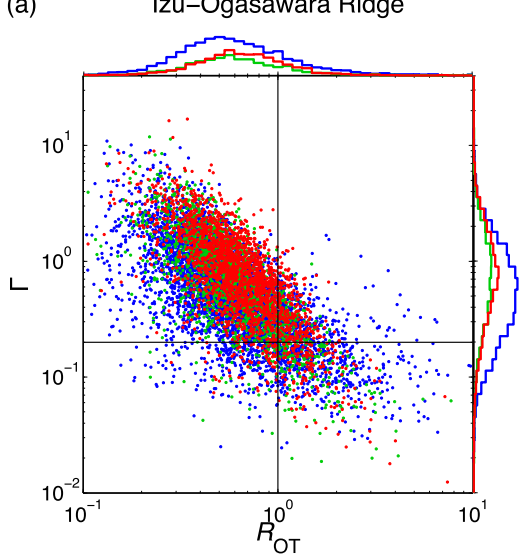

(d)

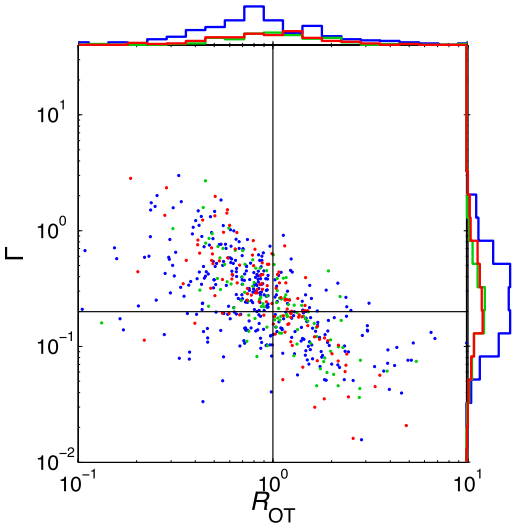

(b)

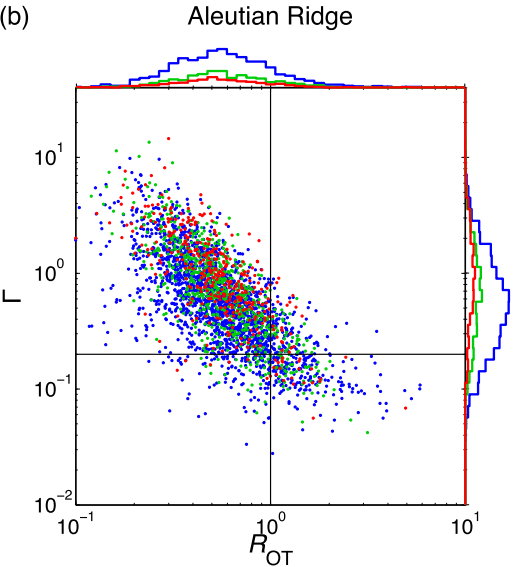

(e)

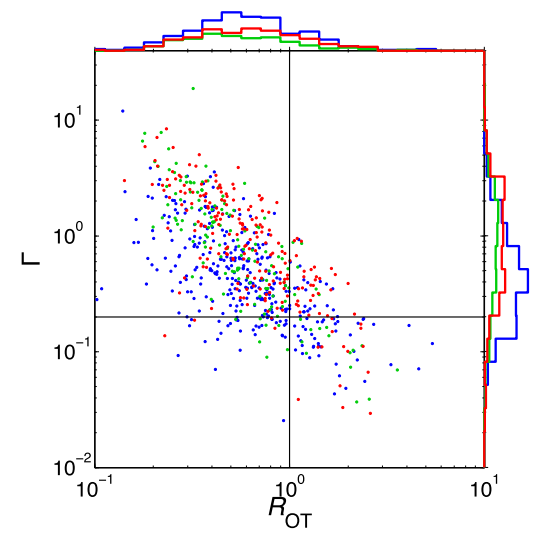

(c)

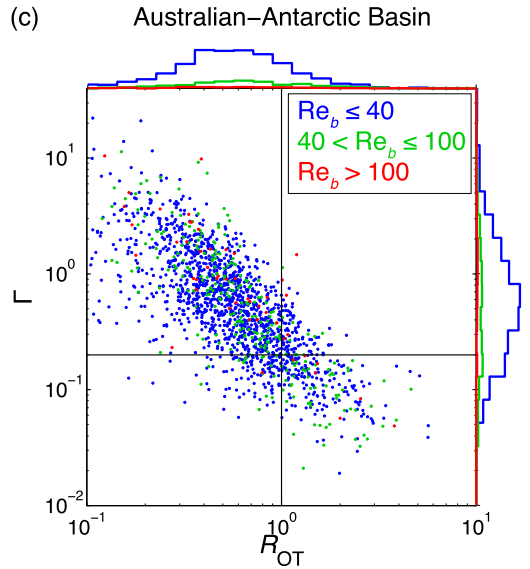

(f)

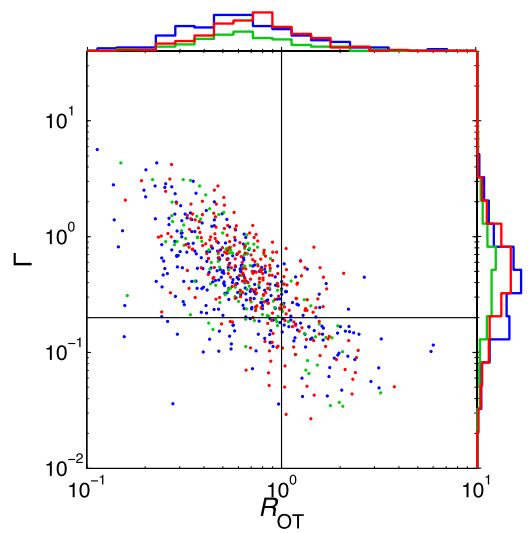

FIG. 7. Observed variations of $\Gamma$ against $R_{\mathrm{OT}}$ classified in terms of regions and $\mathrm{Re}_{b}$ ranges.

$$
L \propto \frac{k_{\mathrm{TKE}}^{3 / 2}}{\varepsilon} .
$$

The mixing length theory (Taylor 1915) expresses the eddy diffusivity in terms of $L[(6)]$ and $k_{\mathrm{TKE}}$ as

$$
K_{\rho} \propto L k_{\mathrm{TKE}}^{1 / 2}
$$

Assuming a linear relationship between $L[(6)]$ and $L_{T}$, we can express both $R_{\mathrm{OT}}$ and $\Gamma$ in terms of the turbulent Froude number $\varepsilon /\left(k_{\mathrm{TKE}} N\right)$ as $R_{\mathrm{OT}}=\left(\varepsilon N^{-3}\right)^{1 / 2} / L_{T} \propto$ $\left[\varepsilon /\left(k_{\mathrm{TKE}} N\right)\right]^{3 / 2}$ and $\Gamma=K_{\rho} /\left(\varepsilon N^{-2}\right) \propto\left[\varepsilon /\left(k_{\mathrm{TKE}} N\right)\right]^{-2}$, respectively, so that we can express $\Gamma$ in terms of $R_{\mathrm{OT}}$ as

$$
\Gamma \propto R_{\mathrm{OT}}^{-4 / 3}
$$

We note that this derivation process is almost the same as found in Baumert and Peters (2004) except for the expression of $K_{\rho}[(7)]$. They incorporated an arbitrary functional dependence into (7) so as to express energy leakage from turbulence to internal waves. However, their formulation was criticized by Kantha and Clayson (2007), so that was not adopted here.
The scaling of $\Gamma[(8)]$ can also be derived from a different approach. From the viewpoint of the energetics of stratified turbulent flows (Scotti and White 2014), $\Gamma$ is regarded as the TAPE/TKE dissipation ratio. Assuming that the dissipation time scales of TAPE and TKE are nearly equal, Scotti (2015) expressed $\Gamma$ as

$$
\Gamma=\frac{k_{\mathrm{TAPE}}}{k_{\mathrm{TKE}}},
$$

where $k_{\mathrm{TAPE}}$ is the TAPE density given by

$$
k_{\mathrm{TAPE}}=\frac{1}{2} N^{2} L^{2} .
$$

Using (6), (9), and (10) together with the assumption of a linear relationship between $L$ and $L_{T}$, we can also obtain the scaling of $\Gamma[(8)]$. Note that the scaling (8) is not applicable to the case of pure convective-driven mixing, for which a linear relationship between $L$ and $L_{T}$ does not hold (Scotti 2015).

This simple theoretical scaling is consistent with the observed negative relationship between $\Gamma$ and $R_{\text {OT }}$ 
(Fig. 8). Since the formulation of $\Gamma$ under the high Reynolds number limit has thus been supported, we argue that $\Gamma$ in the ocean interior should not be scaled in terms of the viscosity-related parameter $\mathrm{Re}_{b}$, particularly in the energetic regime with $\mathrm{Re}_{b}>100$. This argument is consistent with the observations (section 3b) but inconsistent with the DNS studies (Shih et al. 2005; Bouffard and Boegman 2013). Such inconsistency may be explained from the fact that DNS still cannot simulate sufficiently high Reynolds number turbulent flows. Garrett (2001, p. 6) also commented on this point: "Perhaps an apparent dependence of $\Gamma$ on $\varepsilon /\left(\nu N^{2}\right)$ might just be because this parameter is acting as a proxy for some other indicator of mixing strength that does not involve the viscosity $\nu$.' Our results suggest that $R_{\mathrm{OT}}$ is such an indicator of mixing strength. However, this is not the case for boundary layers, where viscosity effects are important for mixing processes (e.g., Tennekes and Lumley 1972). Actually, the decreasing tendency of $\Gamma$ with increasing $\mathrm{Re}_{b}$ was observed in oceanic and atmospheric boundary layers (Davis and Monismith 2011; Lozovatsky and Fernando 2013; Walter et al. 2014). Furthermore, Scotti and White (2016) argued that $\Gamma$ in boundary layers should depend on the MoninObukhov length in addition to $\mathrm{Re}_{b}$.

We note that our theoretical and observational results exhibit the $R_{\mathrm{OT}}$ dependence of $\Gamma$ slightly stronger than Smyth et al. (2001)'s DNS results. We suspect that their DNS might be performed with Reynolds numbers not high enough to quantitatively address $\Gamma$ in the real ocean; actually, their simulated $\Gamma$ depends not only on $R_{\mathrm{OT}}$ but also on the Prandtl number, another viscosity-related parameter. The $R_{\mathrm{OT}}$ dependence of $\Gamma$ should be examined through DNS with much higher Reynolds numbers in the future.

\section{Discussion}

\section{a. Underlying mechanisms of turbulent mixing in the ocean interior}

Combining the results from the previous DNS (Smyth et al. 2001; Scotti 2015) and from our observations (sections $3 \mathrm{a}$ and $3 \mathrm{~b}$ ) gives an insight into possible underlying mechanisms of turbulent mixing in the ocean interior: moderate mixing with $\Gamma \sim O(0.1)$ and $R_{\mathrm{OT}} \sim$ $O(1)$ observed in the upper ocean may reflect the mature stage of shear-driven mixing, whereas efficient mixing with $\Gamma \sim O(1)$ and $R_{\mathrm{OT}} \sim O(0.1)$ observed in the deep ocean may reflect convective-driven mixing and/or the young stage of shear-driven mixing. We expect that the

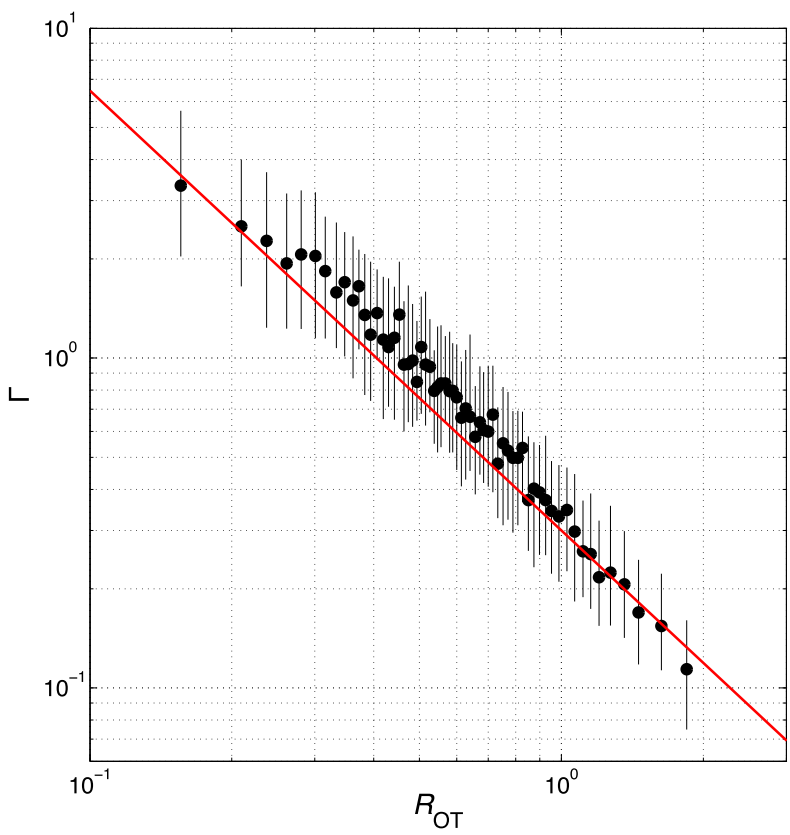

FIG. 8. Observed relationship of $\Gamma$ to $R_{\mathrm{OT}}$ (black dots and bars) and the theoretical scaling $\Gamma \propto R_{\mathrm{OT}}^{-4 / 3}$ (red line). The dots denote median values of $\Gamma$ binned by $R_{\mathrm{OT}}$, while the bars denote the corresponding interquartile ranges. Turbulent patches with $\mathrm{Re}_{b} \leq 40$ are excluded from this averaging process.

shear-driven mixing would reach the mature stage more slowly in the deep ocean than in the upper ocean because the turbulent time scale is negatively related to the stratification in the high Reynolds number limit (Baumert and Peters 2004). In the deep ocean, bottomgenerated internal waves may then break, causing mixing before the previously induced mixing reaches the mature stage and resulting in the observed overall young and efficient mixing. Considering large amplitudes of bottom-generated internal waves, the convective-driven mixing seems to occur in the deep ocean. Nevertheless, the results from the observations (section $3 \mathrm{c}$ ) are consistent with the theoretical scaling of $\Gamma[(8)]$ that is not applicable to the convective-driven mixing, suggesting that the efficient mixing with $\Gamma \sim O(1)$ and $R_{\mathrm{OT}} \sim O(0.1)$ observed in the deep ocean may reflect the young stage of the shear-driven mixing. It should be noted that the moderate mixing with $\Gamma \sim O(0.1)$ and $R_{\mathrm{OT}} \sim O(1)$ is not universal throughout the upper ocean, as in the Luzon Strait where Mater et al. (2015) found small values of $R_{\mathrm{OT}}$ associated with convective collapse of largeamplitude internal waves. Obviously, more observational, numerical, and theoretical studies are necessary to clarify actual mechanisms of turbulent mixing in the ocean interior. 

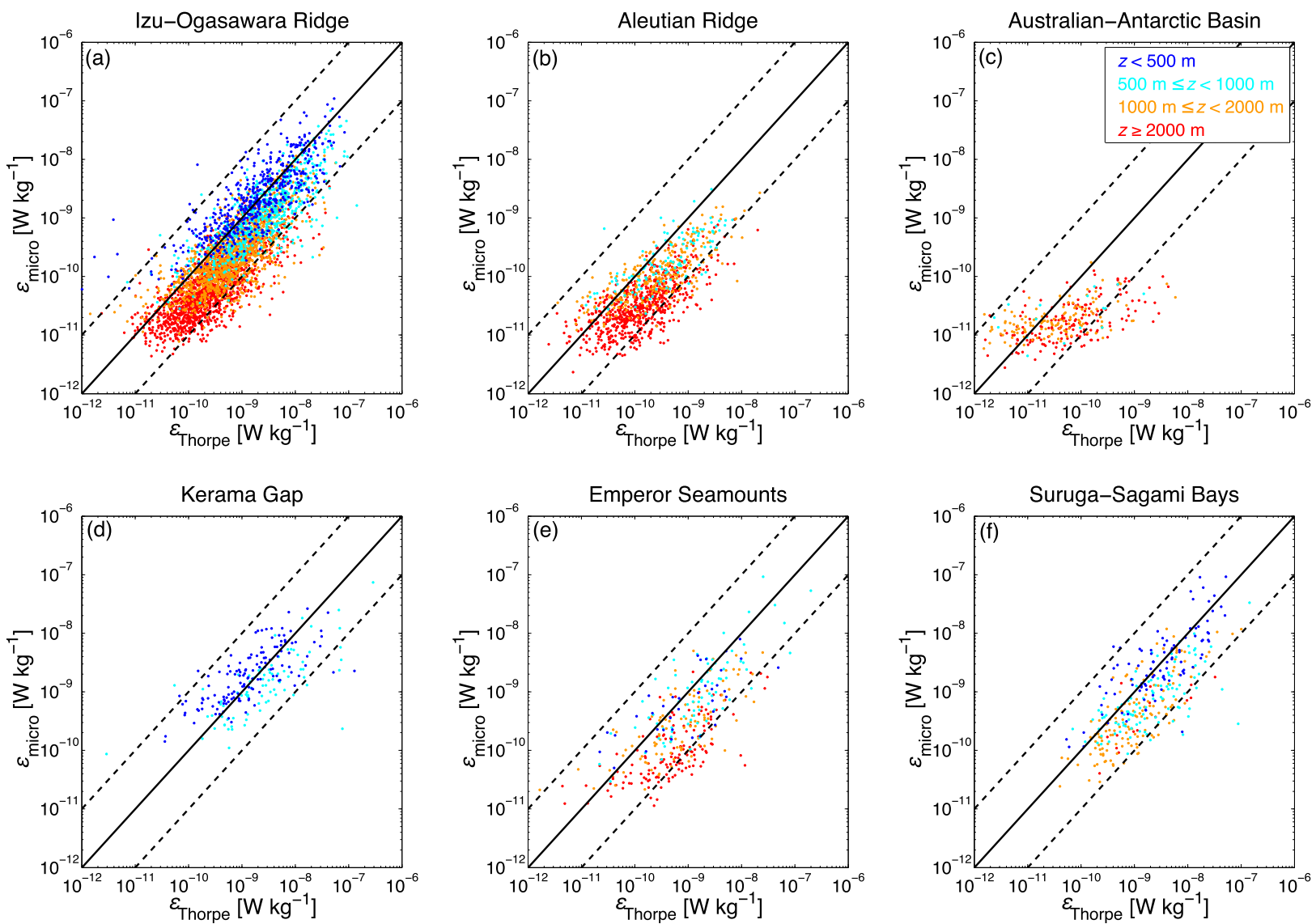

FIG. 9. Scatterplots of microstructure-based estimates of the TKE dissipation rate $\varepsilon_{\text {micro }}$ against its Thorpe-scale-based estimates $\varepsilon_{\text {Thorpe }}$ classified in terms of regions and depth ranges. Here, $\varepsilon_{\text {Thorpe }}$ is estimated from (11) with $R_{\mathrm{OT}}=1$. Turbulent patches with $\mathrm{Re}_{b} \leq 40$ are excluded from these plots.

\section{b. Applicability of the Thorpe-scale-based parameterization of $\varepsilon$}

The constancy of $R_{\mathrm{OT}}$ is the basis for the Thorpescale-based parameterization of $\varepsilon$, as given by

$$
\langle\varepsilon\rangle=R_{\mathrm{OT}}^{2} L_{T}^{2}\langle N\rangle^{3},
$$

where $R_{\mathrm{OT}} \sim 1$ (Dillon 1982) is assumed. Our observations (section $3 \mathrm{~b}$ ), however, have shown the highly variable nature of $R_{\mathrm{OT}}$, as recently pointed out by several authors (Mater et al. 2015; Scotti 2015), so that the Thorpe-scalebased parameterization tends to overestimate $\varepsilon$ by an order of magnitude in the deep ocean in contrast to its high performance in the upper ocean (Fig. 9). Although this parameterization has been applied to various regions for its convenience (e.g., Waterhouse et al. 2014), these results warn about the potential bias of the parameterized values of $\varepsilon$, especially in the deep ocean.

Here, we cannot avoid mentioning inconsistency between this study and Nishina et al. (2016), both of which used the same microstructure profiles collected in the Kerama Gap (section 2a) to assess the Thorpe-scalebased parameterization of $\varepsilon$. Nishina et al. (2016) showed that the parameterization tends to overestimate $\varepsilon$ by an order of magnitude (Fig. 5 of Nishina et al. 2016), whereas this study has shown its high performance in this region (Fig. 9d). We suspect that Nishina et al. (2016) failed to calculate $\langle N\rangle$ in (11) appropriately: $\langle N\rangle$ was calculated not from the bulk gradient (section 2e) but from the smoothed mean gradient $(\mathrm{H}$. Nakamura and A. Nishina 2017, personal communication), so that turbulent patch properties might be lost considerably.

It is also important to note that the $R_{\mathrm{OT}}$ dependence of $\varepsilon$ [(11)] is opposite in sign to that of $\Gamma[(8)]$, making $K_{\rho}$ more insensitive to $R_{\mathrm{OT}}$ than $\varepsilon$ as expressed by

$$
K_{\rho} \propto R_{\mathrm{OT}}^{2 / 3} L_{T}^{2}\langle N\rangle
$$

This study, therefore, suggests that $K_{\rho}[(12)]$ parameterized in terms of the Thorpe scale under the assumption 
of $R_{\mathrm{OT}} \sim 1$ should be less biased than $\varepsilon$ [(11)] despite being parameterized in the same manner, although the Thorpe-scale-based parameterization tends to overestimate even $K_{\rho}$ by a factor of about 2 in the deep ocean.

\section{c. Closure of the global overturning circulation}

It has been generally thought that diapycnal mixing in the ocean interior drives upwelling of deep- and bottomwater masses to form a return flow of the global overturning circulation (Munk 1966). However, this is not true if the buoyancy flux $K_{\rho} N^{2}=\Gamma \varepsilon$ increases with depth, as shown by the diapycnal advection-diffusion balance,

$$
\begin{aligned}
w_{*} & =\frac{1}{N^{2}} \frac{\partial}{\partial z}\left(K_{\rho} N^{2}\right) \\
& =K_{\rho}\left(\frac{1}{\varepsilon} \frac{\partial \varepsilon}{\partial z}+\frac{1}{\Gamma} \frac{\partial \Gamma}{\partial z}\right),
\end{aligned}
$$

where $w *$ is the diapycnal velocity. A recent compilation of previous microstructure measurements (Waterhouse et al. 2014) shows that $\varepsilon$ tends to decrease with depth in the uppermost 2000-3000 $\mathrm{m}$ far from the ocean bottom, but tends to increase with depth in the lowermost 500$1000 \mathrm{~m}$ above the rough ocean bottom. Such a curved vertical profile of $\varepsilon$ leads to upwelling in the thermocline but downwelling near the bottom. In addition, if $\partial \Gamma / \partial z<$ 0 , as suggested in section $3 \mathrm{a}$, is taken into account in (13), the thermocline upwelling would weaken, and the near-bottom downwelling would strengthen. If this is the case, the global overturning circulation could not be sustained only by water mass transport due to interior mixing, suggesting the existence of other processes that can compensate for the net downwelling, such as upwelling along bottom boundary layers (Ferrari et al. 2016; McDougall and Ferrari 2017). Thus, the vertical distribution of $\Gamma$ has potential impacts on closure of the global overturning circulation and should be examined further through more detailed observations.

\section{Conclusions}

It is still controversial whether or not the dissipation flux coefficient $\Gamma$ in the Osborn's eddy diffusivity model is constant throughout the stratified ocean interior. Motivated by lack of observational estimates of $\Gamma$, particularly under weakly stratified deep-ocean conditions, we have examined variations of $\Gamma$ using deep microstructure profiles collected in various regions of the North Pacific and Southern Oceans. We have shown that $\Gamma$ is not constant but varies significantly with the
Ozmidov/Thorpe scale ratio $R_{\mathrm{OT}}$ in a fashion similar to that obtained by the previous DNS study on the evolution of shear-driven mixing (Smyth et al. 2001). Of special notice is that efficient mixing events with $\Gamma \sim O(1)$ and $R_{\mathrm{OT}} \sim O(0.1)$ tend to be frequently observed in the deep ocean (i.e., weak stratification), whereas moderate mixing events with $\Gamma \sim O(0.1)$ and $R_{\mathrm{OT}} \sim O(1)$ tend to be observed in the upper ocean (i.e., strong stratification). Referring to the DNS and theoretical studies (Smyth et al. 2001; Baumert and Peters 2004), we have speculated that the vertical distributions of $\Gamma$ and $R_{\mathrm{OT}}$ thus observed may reflect the stratification dependence of the time required for the shear-driven mixing to reach the mature stage. The observed small values of $R_{\mathrm{OT}}$ and large values of $\Gamma$ in the deep ocean, respectively, imply overestimates of the TKE dissipation rate by the widely used Thorpe-scale-based parameterization and underestimates of $\Gamma$ by the conventional fixed model, resulting in less biased Thorpe-scale-based estimates of eddy diffusivity. The observed vertical distribution of $\Gamma$ implies that upwelling due to interior mixing may be weaker than previously thought. Given the potential importance of these implications, the universality of the observed distributions of $\Gamma$ and $R_{\mathrm{OT}}$ should be checked through many more observations in the near future.

Furthermore, using classical turbulent theories under the high Reynolds number limit, we have derived the simple scaling $\Gamma \propto R_{\mathrm{OT}}^{-4 / 3}$, consistent with the observed negative relationship between $\Gamma$ and $R_{\mathrm{OT}}$. Since the formulation under the high Reynolds number limit has been supported from the observations, we have argued that $\Gamma$ in the ocean interior should not be scaled in terms of the viscosity-related parameter, namely, the buoyancy Reynolds number $\mathrm{Re}_{b}$. This argument is consistent with the observed results exhibiting no definite relationships between $\Gamma$ and $\operatorname{Re}_{b}$. Note that this is not the case for boundary layers, where viscosity effects are actually important for mixing processes. Of course, relationships of $\Gamma$ to other parameters, such as the Richardson number, should be examined in the future for its better scaling.

Admittedly, the above conclusions are based on indirect estimates of $\Gamma$; the TAPE dissipation rate is approximated in terms of the thermal variance dissipation rate, ${ }^{2}$ so that estimated $\Gamma$ might be biased under the presence of differential diffusion or double diffusion. However, we believe that our observed results are not largely biased since we have discarded data favorable to differential diffusion (Jackson and Rehmann 2014) and double diffusion (St. Laurent and Schmitt 1999) using

\footnotetext{
${ }^{2}$ Remember that $\Gamma$ is defined as the TAPE/TKE dissipation ratio.
} 

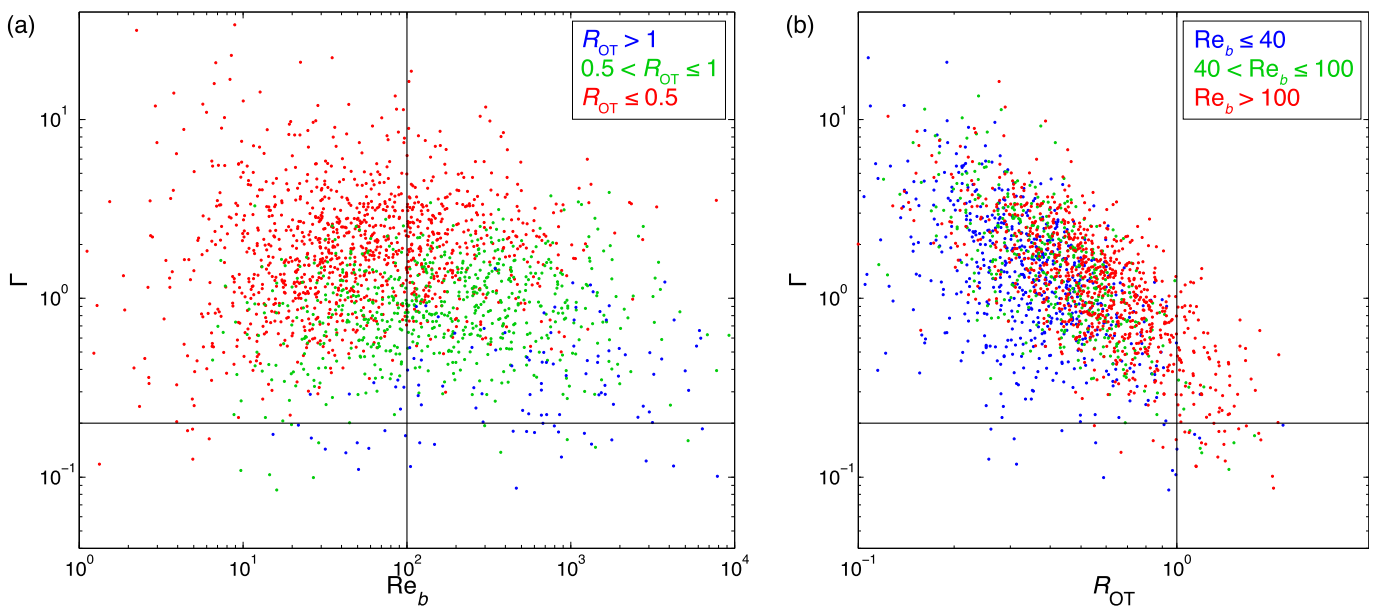

FIG. A1. Scatterplots of $\Gamma$ against (a) $\mathrm{Re}_{b}$ and (b) $R_{\mathrm{OT}}$ for the case of $0.8<\left\langle\Theta_{z}\right\rangle_{\text {mean }} /\left\langle\Theta_{z}\right\rangle_{\text {bulk }}<1.2$.

$\mathrm{Re}_{b}$ and the density stability ratio. Another concerning issue is that observations cannot deal with a threedimensionally sorted density field, from which the background stratification should be ideally calculated (Scotti and White 2014). Using DNS, Arthur et al. (2017) showed that the usual method to calculate the background stratification from a locally sorted vertical density profile yields biased estimates of $\Gamma$ in an inhomogeneous turbulent flow near a boundary. Nevertheless, we believe that this does not seriously matter in the ocean interior, most of our observed oceanic environments, where locally homogeneous turbulence would dominate.

Acknowledgments. This study was supported by MEXT KAKENHI Grant JP15H05824 and JSPS KAKENHI Grant JP15H02131. The authors express their gratitude to two anonymous reviewers for their invaluable comments on the original manuscript. Data used for producing the results herein may be requested by contacting the authors.

\section{APPENDIX}

\section{Validity of Patch-Averaged Stratification Estimates}

As described in section $2 \mathrm{e}$, we used $\left\langle\Theta_{z}\right\rangle_{\text {bulk }}$ for the estimate of the Ozmidov scale $L_{O}$ while using $\left\langle\Theta_{z}\right\rangle_{\text {mean }}$ for the estimate of $\Gamma[(3)]$. Here, we examine the validity of our selection of $\left\langle\Theta_{z}\right\rangle$. Figure A1 shows scatterplots of $\Gamma$ against $\mathrm{Re}_{b}$ and $R_{\mathrm{OT}}$ for the case that both gradients are nearly equal (specifically, $0.8<\left\langle\Theta_{z}\right\rangle_{\text {mean }} /\left\langle\Theta_{z}\right\rangle_{\text {bulk }}<1.2$ ), which are quite similar to those in Figs. 6 and 7. No definite relationships can be found between $\Gamma$ and $\operatorname{Re}_{b}$ (Fig. A1a), whereas a significant negative relationship can be found between $\Gamma$ and $R_{\mathrm{OT}}$ (Fig. A1b), supporting the validity of our selection of $\left\langle\Theta_{z}\right\rangle$.

\section{REFERENCES}

Anderson, S. P., 1993: Shear, strain and thermohaline vertical fine structure in the upper ocean. Ph.D. thesis, University of California, San Diego, Scripps Institution of Oceanography, 187 pp., http://www.dtic.mil/docs/citations/ADA265961/.

Arthur, R. S., S. K. Venayagamoorthy, J. R. Koseff, and O. B. Fringer, 2017: How we compute $N$ matters to estimates of mixing in stratified flows. J. Fluid Mech., 831, R2, https:// doi.org/10.1017/jfm.2017.679.

Baumert, H., and H. Peters, 2004: Turbulence closure, steady state, and collapse into waves. J. Phys. Oceanogr., 34, 505-512, https:// doi.org/10.1175/1520-0485(2004)034<0505:TCSSAC $>2.0$. CO;2.

Bluteau, C. E., N. L. Jones, and G. N. Ivey, 2013: Turbulent mixing efficiency at an energetic ocean site. J. Geophys. Res. Oceans, 118, 4662-4672, https://doi.org/10.1002/jgrc.20292.

, R. G. Lueck, G. N. Ivey, N. L. Jones, J. W. Book, and A. E. Rice, 2017: Determining mixing rates from concurrent temperature and velocity measurements. J. Atmos. Oceanic Technol., 34, 22832293, https://doi.org/10.1175/JTECH-D-16-0250.1.

Bogucki, D. J., H. Luo, and J. A. Domaradzki, 2012: Experimental evidence of the Kraichnan scalar spectrum at high Reynolds numbers. J. Phys. Oceanogr., 42, 1717-1728, https://doi.org/ 10.1175/JPO-D-11-0214.1.

Bouffard, D., and L. Boegman, 2013: A diapycnal diffusivity model for stratified environmental flows. Dyn. Atmos. Oceans, 61-62, 14-34, https://doi.org/10.1016/j.dynatmoce.2013.02.002.

Davis, K. A., and S. G. Monismith, 2011: The modification of bottom boundary layer turbulence and mixing by internal waves shoaling on a barrier reef. J. Phys. Oceanogr., 41, 2223 2241, https://doi.org/10.1175/2011JPO4344.1.

de Lavergne, C., G. Madec, J. L. Sommer, A. J. G. Nurser, and A. C. Naveira Garabato, 2016: The impact of a variable mixing efficiency on the abyssal overturning. J. Phys. Oceanogr., 46, 663-681, https://doi.org/10.1175/JPO-D-14-0259.1.

Dillon, T. M., 1982: Vertical overturns: A comparison of Thorpe and Ozmidov length scales. J. Geophys. Res., 87, 9601-9613, https://doi.org/10.1029/JC087iC12p09601. 
Fer, I., E. Darelius, and K. B. Daae, 2016: Observations of energetic turbulence on the Weddell Sea continental slope. Geophys. Res. Lett., 43, 760-766, https://doi.org/10.1002/ 2015 GL067349.

Ferrari, R., A. Mashayek, T. J. McDougall, M. Nikurashin, and J.-M. Campin, 2016: Turning ocean mixing upside down. J. Phys. Oceanogr., 46, 2239-2261, https://doi.org/10.1175/ JPO-D-15-0244.1.

Garrett, C., 2001: Stirring and mixing: What are the ratecontrolling processes? From Stirring to Mixing in a Stratified Ocean: Proc. 'Aha Huliko'a Hawaiian Winter Workshop, Honolulu, HI, University of Hawai'i at Mānoa, 1-8, http:// www.soest.hawaii.edu/PubServices/2001pdfs/TOC2001.html.

Goodman, L., E. R. Levine, and R. G. Lueck, 2006: On measuring the terms of the turbulent kinetic energy budget from an AUV.J. Atmos. Oceanic Technol., 23, 977-990, https://doi.org/ 10.1175/JTECH1889.1

Goto, Y., I. Yasuda, and M. Nagasawa, 2016: Turbulence estimation using fast-response thermistors attached to a free-fall vertical microstructure profiler. J. Atmos. Oceanic Technol., 33, 2065-2078, https://doi.org/10.1175/JTECH-D-15-0220.1.

Gregg, M. C., and J. K. Horne, 2009: Turbulence, acoustic backscatter, and pelagic nekton in Monterey Bay. J. Phys. Oceanogr., 39, 1097-1114, https://doi.org/10.1175/2008JPO4033.1.

_ ciency in the ocean. Annu. Rev. Mar. Sci., 10, 443-473, https:// doi.org/10.1146/annurev-marine-121916-063643.

Hibiya, T., M. Nagasawa, and Y. Niwa, 2002: Nonlinear energy transfer within the oceanic internal wave spectrum at mid and high latitudes. J. Geophys. Res., 107, 3207, https://doi.org/ 10.1029/2001JC001210.

Horne, E. P. W., and J. M. Toole, 1980: Sensor response mismatches and lag correction techniques for temperature-salinity profilers. J. Phys. Oceanogr., 10, 1122-1130, https://doi.org/10.1175/15200485(1980)010<1122:SRMALC $>2.0 . C O ; 2$.

Inall, M. E., T. P. Rippeth, and T. J. Sherwin, 2000: Impact of nonlinear waves on the dissipation of internal tidal energy at a shelf break. J. Geophys. Res., 105, 8687-8705, https://doi.org/ 10.1029/1999JC900299.

Jackson, P. R., and C. R. Rehmann, 2014: Experiments on differential scalar mixing in turbulence in a sheared, stratified flow. J. Phys. Oceanogr., 44, 2661-2680, https://doi.org/10.1175/ JPO-D-14-0027.1.

Jayne, S. R., 2009: The impact of abyssal mixing parameterizations in an ocean general circulation model. J. Phys. Oceanogr., 39, 1756-1775, https://doi.org/10.1175/2009JPO4085.1.

Kantha, L. H., and C. A. Clayson, 2007: On leakage of energy from turbulence to internal waves in the oceanic mixed layer. Ocean Dyn., 57, 151-156, https://doi.org/10.1007/s10236-006-0100-3.

Kitade, Y., and M. Matsuyama, 1997: Characteristics of internal tides in the upper layer of Sagami Bay. J. Oceanogr., 53, 143159, https://www.terrapub.co.jp/journals/JO/abstract/5302/ 53020143.html.

Kunze, E., and J. M. Toole, 1997: Tidally driven vorticity, diurnal shear, and turbulence atop Fieberling Seamount. J. Phys. Oceanogr., 27, 2663-2693, https://doi.org/10.1175/1520-0485 (1997)027<2663:TDVDSA > 2.0.CO;2.

Ledwell, J. R., E. T. Montgomery, K. L. Polzin, L. C. St. Laurent, R. W. Schmitt, and J. M. Toole, 2000: Evidence for enhanced mixing over rough topography in the abyssal ocean. Nature, 403, 179-182, https://doi.org/10.1038/35003164.

, L. C. St. Laurent, J. B. Girton, and J. M. Toole, 2011: Diapycnal mixing in the Antarctic Circumpolar Current.
J. Phys. Oceanogr., 41, 241-246, https://doi.org/10.1175/ 2010JPO4557.1.

Lozovatsky, I. D., and H. J. S. Fernando, 2013: Mixing efficiency in natural flows. Philos. Trans. Roy. Soc. London, 371, 20120213 , https://doi.org/10.1098/rsta.2012.0213.

Lueck, R. G., and J. J. Picklo, 1990: Thermal inertia of conductivity cells: Observations with a Sea-Bird cell. J. Atmos. Oceanic Technol., 7, 756-768, https://doi.org/10.1175/1520-0426(1990) 007<0756:TIOCCO >2.0.CO;2.

Macoun, P., and R. Lueck, 2004: Modeling the spatial response of the airfoil shear probe using different sized probes. J. Atmos. Oceanic Technol., 21, 284-297, https://doi.org/ 10.1175/1520-0426(2004)021<0284:MTSROT>2.0.CO;2.

Mashayek, A., and W. R. Peltier, 2013: Shear-induced mixing in geophysical flows: Does the route to turbulence matter to its efficiency? J. Fluid Mech., 725, 216-261, https://doi.org/ 10.1017/jfm.2013.176.

— C. P. Caulfield, and W. R. Peltier, 2013: Time-dependent, nonmonotonic mixing in stratified turbulent shear flows: Implications for oceanographic estimates of buoyancy flux. J. Fluid Mech., 736, 570-593, https://doi.org/10.1017/jfm.2013.551.

—, H. Salehipour, D. Bouffard, C. P. Caulfield, R. Ferrari, M. Nikurashin, W. R. Peltier, and W. D. Smyth, 2017: Efficiency of turbulent mixing in the abyssal ocean circulation. Geophys. Res. Lett., 44, 6296-6306, https://doi.org/10.1002/ 2016 GL072452.

Mater, B. D., S. K. Venayagamoorthy, L. St. Laurent, and J. N. Moum, 2015: Biases in Thorpe-scale estimates of turbulence dissipation. Part I: Assessments from large-scale overturns in oceanographic data. J. Phys. Oceanogr., 45, 2497-2521, https:// doi.org/10.1175/JPO-D-14-0128.1.

Matsuyama, M., S. Ohta, T. Hibiya, and H. Yamada, 1993: Strong tidal currents observed near the bottom in the Suruga Trough, central Japan. J. Oceanogr., 49, 683-696, https://doi.org/ 10.1007/BF02276752.

McComas, C. H., and F. P. Bretherton, 1977: Resonant interaction of oceanic internal waves. J. Geophys. Res., 82, 1397-1412, https://doi.org/10.1029/JC082i009p01397.

McDougall, T. J., and R. Ferrari, 2017: Abyssal upwelling and downwelling driven by near-boundary mixing. J. Phys. Oceanogr., 47, 261-283, https://doi.org/10.1175/JPO-D-16-0082.1.

Mead Silvester, J., Y.-D. Lenn, J. A. Polton, T. P. Rippeth, and M. Morales Maqueda, 2014: Observations of a diapycnal shortcut to adiabatic upwelling of Antarctic Circumpolar Deep Water. Geophys. Res. Lett., 41, 7950-7956, https:// doi.org/10.1002/2014GL061538.

Melet, A., R. Hallberg, S. Legg, and K. Polzin, 2013: Sensitivity of the ocean state to the vertical distribution of internal-tidedriven mixing. J. Phys. Oceanogr., 43, 602-615, https://doi.org/ 10.1175/JPO-D-12-055.1.

,,,--- and M. Nikurashin, 2014: Sensitivity of the ocean state to lee wave-driven mixing. J. Phys. Oceanogr., 44, 900 921, https://doi.org/10.1175/JPO-D-13-072.1.

Morison, J., R. Andersen, N. Larson, E. D'Asaro, and T. Boyd, 1994: The correction for thermal-lag effects in Sea-Bird CTD data. J. Atmos. Oceanic Technol., 11, 1151-1164, https:// doi.org/10.1175/1520-0426(1994)011<1151:TCFTLE > 2.0.CO;2.

Moum, J. N., 1996: Efficiency of mixing in the main thermocline. J. Geophys. Res., 101, 12 057-12 069, https://doi.org/10.1029/ 96JC00508.

Munk, W. H., 1966: Abyssal recipes. Deep-Sea Res. Oceanogr. Abstr., 13, 707-730, https://doi.org/10.1016/0011-7471(66) 90602-4. 
— and wind mixing. Deep-Sea Res. I, 45, 1977-2010, https:// doi.org/10.1016/S0967-0637(98)00070-3.

Nakamura, H., A. Nishina, Z. Liu, F. Tanaka, M. Wimbush, and J.-H. Park, 2013: Intermediate and deep water formation in the Okinawa Trough. J. Geophys. Res. Oceans, 118, 68816893, https://doi.org/10.1002/2013JC009326.

Nishina, A., H. Nakamura, J.-H. Park, D. Hasegawa, Y. Tanaka, S. Seo, and T. Hibiya, 2016: Deep ventilation in the Okinawa Trough induced by Kerama Gap overflow. J. Geophys. Res. Oceans, 121, 6092-6102, https://doi.org/ 10.1002/2016JC011822.

Niwa, Y., and T. Hibiya, 2014: Generation of baroclinic tide energy in a global three-dimensional numerical model with different spatial grid resolutions. Ocean Modell., 80, 59-73, https://doi.org/10.1016/j.ocemod.2014.05.003.

Oakey, N. S., 1982: Determination of the rate of dissipation of turbulent energy from simultaneous temperature and velocity shear microstructure measurements. J. Phys. Oceanogr., 12, 256-271, https://doi.org/10.1175/1520-0485(1982)012<0256: DOTROD $>2.0 . \mathrm{CO} ; 2$

_ and B. J. W. Greenan, 2004: Mixing in a coastal environment: 2. A view from microstructure measurements. J. Geophys. Res., 109, C10014, https://doi.org/10.1029/2003JC002193.

Ohwaki, A., M. Matsuyama, and S. Iwata, 1991: Evidence for predominance of internal tidal currents in Sagami and Suruga Bays. J. Oceanogr. Soc. Japan, 47, 194-206, https://doi.org/ 10.1007/BF02310035.

Osborn, T. R., 1980: Estimates of the local rate of vertical diffusion from dissipation measurements. J. Phys. Oceanogr., 10, 83-89, https://doi.org/10.1175/1520-0485(1980)010<0083: EOTLRO $>2.0 . \mathrm{CO} ; 2$.

_ and C. S. Cox, 1972: Oceanic fine structure. Geophys. Fluid Dyn., 3, 321-345, https://doi.org/10.1080/03091927208236085.

Ozmidov, R. V., 1965: On the turbulent exchange in a stably stratified ocean. Izv. Acad. Sci. USSR, Atmos. Oceanic Phys., 1, 853-860.

Palmer, M. R., T. P. Rippeth, and J. H. Simpson, 2008: An investigation of internal mixing in a seasonally stratified shelf sea. J. Geophys. Res., 113, C12005, https://doi.org/10.1029/ 2007JC004531.

Peltier, W. R., and C. P. Caulfield, 2003: Mixing efficiency in stratified shear flows. Annu. Rev. Fluid Mech., 35, 135-167, https://doi.org/10.1146/annurev.fluid.35.101101.161144.

Peters, H., and M. C. Gregg, 1988: Some dynamical and statistical properties of equatorial turbulence. Small-Scale Turbulence and Mixing in the Ocean, J. C. J. Nihoul and B. M. Jamart, Eds., Elsevier Oceanography Series, Vol. 46, Elsevier, 185200, https://doi.org/10.1016/S0422-9894(08)70546-4.

Peterson, A. K., and I. Fer, 2014: Dissipation measurements using temperature microstructure from an underwater glider. Methods Oceanogr., 10, 44-69, https://doi.org/ 10.1016/j.mio.2014.05.002.

Rainville, L., and P. Winsor, 2008: Mixing across the Arctic Ocean: Microstructure observations during the Beringia 2005 Expedition. Geophys. Res. Lett., 35, L08606, https://doi.org/10.1029/ 2008 GL033532.

Ruddick, B., D. Walsh, and N. Oakey, 1997: Variations in apparent mixing efficiency in the North Atlantic Central Water. J. Phys. Oceanogr., 27, 2589-2605, https://doi.org/10.1175/1520-0485(1997) 027<2589:VIAMEI $>2.0 . \mathrm{CO} ; 2$.

Salehipour, H., C. P. Caulfield, and W. R. Peltier, 2016: Turbulent mixing due to the Holmboe wave instability at high Reynolds number. J. Fluid Mech., 803, 591-621, https://doi.org/10.1017/ jfm.2016.488.

Scotti, A., 2015: Biases in Thorpe-scale estimates of turbulence dissipation. Part II: Energetics arguments and turbulence simulations. J. Phys. Oceanogr., 45, 2522-2543, https://doi.org/ 10.1175/JPO-D-14-0092.1.

- and B. White, 2014: Diagnosing mixing in stratified turbulent flows with a locally defined available potential energy. J. Fluid Mech., 740, 114-135, https://doi.org/10.1017/jfm.2013.643.

- and - 2016: The mixing efficiency of stratified turbulent boundary layers. J. Phys. Oceanogr., 46, 3181-3191, https:// doi.org/10.1175/JPO-D-16-0095.1.

Sheen, K. L., and Coauthors, 2013: Rates and mechanisms of turbulent dissipation and mixing in the Southern Ocean: Results from the Diapycnal and Isopycnal Mixing Experiment in the Southern Ocean (DIMES). J. Geophys. Res. Oceans, 118, 2774-2792, https://doi.org/10.1002/jgrc.20217.

Shih, L. H., J. R. Koseff, G. N. Ivey, and J. H. Ferziger, 2005: Parameterization of turbulent fluxes and scales using homogeneous sheared stably stratified turbulence simulations. J. Fluid Mech., 525, 193-214, https://doi.org/10.1017/ S0022112004002587.

Simpson, J. H., N. S. Lucas, B. Powell, and S. C. Maberly, 2015: Dissipation and mixing during the onset of stratification in a temperate lake, Windermere. Limnol. Oceanogr., 60, 29-41, https://doi.org/10.1002/lno.10008.

Smyth, W. D., J. N. Moum, and D. R. Caldwell, 2001: The efficiency of mixing in turbulent patches: Inferences from direct simulations and microstructure observations. J. Phys. Oceanogr., 31, 1969-1992, https://doi.org/10.1175/1520-0485(2001) 031<1969:TEOMIT >2.0.CO;2.

St. Laurent, L., and R. W. Schmitt, 1999: The contribution of salt fingers to vertical mixing in the North Atlantic Tracer Release Experiment. J. Phys. Oceanogr., 29, 1404-1424, https://doi.org/ 10.1175/1520-0485(1999)029<1404:TCOSFT > 2.0.CO;2.

—, A. C. Naveira Garabato, J. R. Ledwell, A. M. Thurnherr, J. M. Toole, and A. J. Watson, 2012: Turbulence and diapycnal mixing in Drake Passage. J. Phys. Oceanogr., 42, 2143-2152, https://doi.org/10.1175/JPO-D-12-027.1.

Taylor, G. I., 1915: Eddy motion in the atmosphere. Philos. Trans. Roy. Soc. London, 215, 1-26, https://doi.org/10.1098/ rsta.1915.0001.

, 1935: Statistical theory of turbulence. Proc. Roy. Soc. London, 151, 421-444, https://doi.org/10.1098/rspa.1935.0158.

Tennekes, H., and J. L. Lumley, 1972: A First Course in Turbulence. MIT Press, 300 pp.

Thorpe, S. A., 1977: Turbulence and mixing in a Scottish Loch. Philos. Trans. Roy. Soc. London, 286, 125-181, https://doi.org/ 10.1098/rsta.1977.0112

Toole, J. M., R. W. Schmitt, K. L. Polzin, and E. Kunze, 1997: Near-boundary mixing above the flanks of a midlatitude seamount. J. Geophys. Res., 102, 947-959, https://doi.org/ 10.1029/96JC03160.

Venayagamoorthy, S. K., and J. R. Koseff, 2016: On the flux Richardson number in stably stratified turbulence. J. Fluid Mech., 798, R1, https://doi.org/10.1017/jfm.2016.340.

Walter, R. K., M. E. Squibb, C. B. Woodson, J. R. Koseff, and S. G. Monismith, 2014: Stratified turbulence in the nearshore coastal ocean: Dynamics and evolution in the presence of internal bores. J. Geophys. Res. Oceans, 119, 8709-8730, https:// doi.org/10.1002/2014JC010396.

Waterhouse, A. F., and Coauthors, 2014: Global patterns of diapycnal mixing from measurements of the turbulent dissipation 
rate. J. Phys. Oceanogr., 44, 1854-1872, https://doi.org/ 10.1175/JPO-D-13-0104.1.

Waterman, S., A. C. Naveira Garabato, and K. L. Polzin, 2013: Internal waves and turbulence in the Antarctic Circumpolar Current. J. Phys. Oceanogr., 43, 259-282, https://doi.org/ 10.1175/JPO-D-11-0194.1.

Winters, K. B., P. N. Lombard, J. J. Riley, and E. A. D'Asaro, 1995: Available potential energy and mixing in density-stratified fluids. J. Fluid Mech., 289, 115-128, https://doi.org/10.1017/ S002211209500125X.

Wolk, F., H. Yamazaki, L. Seuront, and R. G. Lueck, 2002: A new free-fall profiler for measuring biophysical microstructure.
J. Atmos. Oceanic Technol., 19, 780-793, https://doi.org/10.1175/ 1520-0426(2002)019<0780:ANFFPF>2.0.CO;2.

Wunsch, C., and R. Ferrari, 2004: Vertical mixing, energy, and the general circulation of the oceans. Annu. Rev. Fluid Mech., 36, 281-314, https://doi.org/10.1146/ annurev.fluid.36.050802.122121.

Yamazaki, H., and T. Osborn, 1990: Dissipation estimates for stratified turbulence. J. Geophys. Res., 95, 9739-9744, https:// doi.org/10.1029/JC095iC06p09739.

- and - 1993: Direct estimation of heat flux in a seasonal thermocline. J. Phys. Oceanogr., 23, 503-516, https://doi.org/ 10.1175/1520-0485(1993)023<0503:DEOHFI >2.0.CO;2. 